\title{
Peer-Led Point-of-Care Ultrasound: a Potential Ally to Rural Medicine
}

\author{
Michel Khoury, Shankar Sethuraman, Samuel Wilson
}

Faculty of Medicine, University of Ottawa, Ottawa, Ontario, Canada

ABSTRACT

Objective: Point-of-care ultrasound (POCUS) is increasingly used in rural settings where its portability and imaging capabilities make it effective clinically. POCUS teaching has traditionally relied on faculty instruction, which is limited by the small number of certified faculty members. The University of Ottawa POCUS interest group deployed peer-teaching in 2018, which overcomes the instructor barrier by employing experienced medical students to train pre-clerkship students. This paper will explore student perceptions around peer-led POCUS workshops as a learning format.

Methods: 3-hour POCUS workshops were held for cardiac, MSK, aorta, and eFAST scans from October 2018 to June 2019. Students with prior experience in POCUS were identified as peer-teachers and were trained by an expert physician prior to the workshop. Peer-teachers taught a small group, with physician experts rotating through groups for technical support.

Surveys were sent out to students who participated in the workshops assessing the following categories: utility, learning experience, workshop efficacy, tutor competence, and interest. Descriptive statistics and thematic analysis was reported for the quantitative and qualitative data, respectively.

Results: 45 participants completed the survey. The surveys showed positive support for the aforementioned categories, with the average score being greater than 4 on 5 on the Likert scale. From the thematic analysis, the four main strengths of the peer-led format were: trainer competence, learner comfort, situational teaching, and opportunity to practice.

Conclusion: Peer-led workshops are an effective format for POCUS training in instructor-constrained settings. These workshops can be translated to rural settings in lieu of a formal POCUS training program.

\section{RÉSUMÉ}

Objective: L'échographie ciblée (POCUS) est de plus en plus utilisée en milieu rural où sa portabilité et ses capacités d'imagerie lui confèrent une efficacité clinique. L'enseignement POCUS s'appuie traditionnellement sur la formation offerte par des professeurs, ce qui est souvent limité par le petit nombre de membres certifiés au sein du corps professoral. Le groupe d'intérêt POCUS de I'Université d'Ottawa a déployé l'enseignement par les pairs en 2018, ce qui permet de surmonter l'obstacle des instructeurs en embauchant des étudiants en médecine expérimentés pour former des étudiants au pré-externat. Ce document explorera les perceptions des étudiants sur les ateliers POCUS dirigés par les pairs en tant que forme d'apprentissage.

Méthodes Des ateliers POCUS de trois heures ont été organisés d'octobre 2018 à juin 2019 pour les examens cardiaques, MSK, aorte et eFAST. Les pairs-enseignants ont enseigné à un petit groupe, tout en présence de médecins experts afin d'obtenir du soutien technique. Des sondages ont ensuite été envoyés aux étudiants ayant participé aux ateliers afin d'évaluer les catégories suivantes : utilité, expérience d'apprentissage, efficacité de l'atelier, compétence du tuteur et intérêt général. Des statistiques descriptives et une analyse thématique ont été rapportées pour les données quantitatives et qualitatives, respectivement.

Résultats: 45 participants ont répondu au sondage. Les sondages ont montré un soutien positif pour les catégories mentionnées auparavant, le score moyen étant supérieur à 4 sur 5 sur l'échelle de Likert. D'après l'analyse thématique, les quatre principaux atouts du format dirigé par les pairs étaient : la compétence du formateur, le confort de l'apprenant, la mise en situation et la possibilité de pratiquer.

Conclusion : Les ateliers dirigés par les pairs sont un format efficace pour la formation POCUS dans des environnements soumis à des contraintes d'instructeur. Ces ateliers peuvent être conduits en milieu rural au lieu d'un programme de formation POCUS formel.

Keywords: Point-of-care Ultrasound, Innovation, Pre-Clerkship, Peer-Teaching 
$\mathbf{T}$ hroughout their careers, doctors continuously partake in mentoring roles while actively contributing to the education of medical students, residents and newly graduated physicians. This echoes the philosophy that medical education is based on the vertical transmission of knowledge from peers and colleagues, which provides a substantial portion of one's training. Hence, peer-teaching competency should be introduced early on in medical education.

Peer teachers are defined as individuals from similar social groupings, who are not professional pedagogues, that help each other to learn a specific subject while enhancing their own knowledge by doing so (1). Peer teachers in medical school are usually comprised of fellow students that have less knowledge than licensed physicians, with little to no formal teaching experience $(2,3)$. Despite this, studies show that peer teaching has a positive impact on both tutors and tutees $(2,3)$. Furthermore, a review concluded that knowledge transmission was similar whether students were taught by faculty or by peers (2). Peer teaching is also a prevalent didactic modality, with nearly $50 \%$ of American medical schools using it in their curriculum (4). Compared with conventional faculty members, peer tutors can more appropriately frame the complexity of their lessons around students' level of understanding $(3,5-7)$, fostering a more comfortable and collaborative environment while connecting with students on a more personal level.

Historically, peer mentoring in medical education has been implemented for problem-based learning sessions, clinical skills teachings and in lectures (2). Recently, medical schools have started using this teaching paradigm for more novel subjects, such as point-of-care ultrasound (POCUS). POCUS is where clinicians scan patients at the bedside with ultrasound to aid in diagnosis. With recent advances in portability and affordability, POCUS is allowing clinicians from a wide array of specialties to use it at the bedside (8), allowing realtime imaging, with minimal risks to the patient (9). POCUS requires the ability to properly use the ultrasound machine, understand the patient's anatomy, effectively handle the ultrasound probe, generate adequate images and perform the proper interpretation of the images based on knowledge of ultrasound physics and internal anatomy. It is an advanced technical skill that historically required clinicians to complete intensive 30-hour ultrasound scanning workshops to become competent, along with years of experience performing scans to become an expert. POCUS is a hands-on skill, so it is difficult to master through didactic methods and is best taught in an interactive manner in a small group course. Historically, POCUS courses were led by POCUS competent clinical staff. However, there is a limited number of POCUS experts available so it may not be possible to leverage their expertise to run regular POCUS courses. The use of peer mentors for POCUS education has been proposed as a solution to decrease the number of physicians required for a teaching session, providing alternatives for faculty or resources-deprived settings such as the rural healthcare environment (10).

At the University of Ottawa, curricular exposure to POCUS is very limited. Consequently, the majority of the POCUS teaching was done in an extracurricular manner, with the newly created POCUS interest group that employed a peerteaching approach. A recent scoping review evaluating the novel integration of POCUS in medical education found

Table 1. Open-ended Questionnaire Responses Categorized into Common Themes

\begin{tabular}{|c|c|c|c|}
\hline Category & Theme & $\begin{array}{l}\text { Number of } \\
\text { comments }\end{array}$ & Examples \\
\hline \multirow[t]{6}{*}{ Positive feedback } & Teacher competence & 7 & "The trainers were fantastic at demon-strating scans" \\
\hline & Learner comfort & 4 & $\begin{array}{l}\text { "I felt I was able to go at my own pace with no pressure to impress } \\
\text { a physician" }\end{array}$ \\
\hline & Situational teaching & 4 & $\begin{array}{l}\text { "It was good to learn scans relevant to the systems we are study- } \\
\text { ing" }\end{array}$ \\
\hline & & & "Cardiac scans during cardiac block was a great idea" \\
\hline & Opportunity to practice & 3 & "The teachers would stay as late as we needed them" \\
\hline & & & $\begin{array}{l}\text { "I felt like I had as much scanning time as I needed to get com- } \\
\text { fortable" }\end{array}$ \\
\hline
\end{tabular}




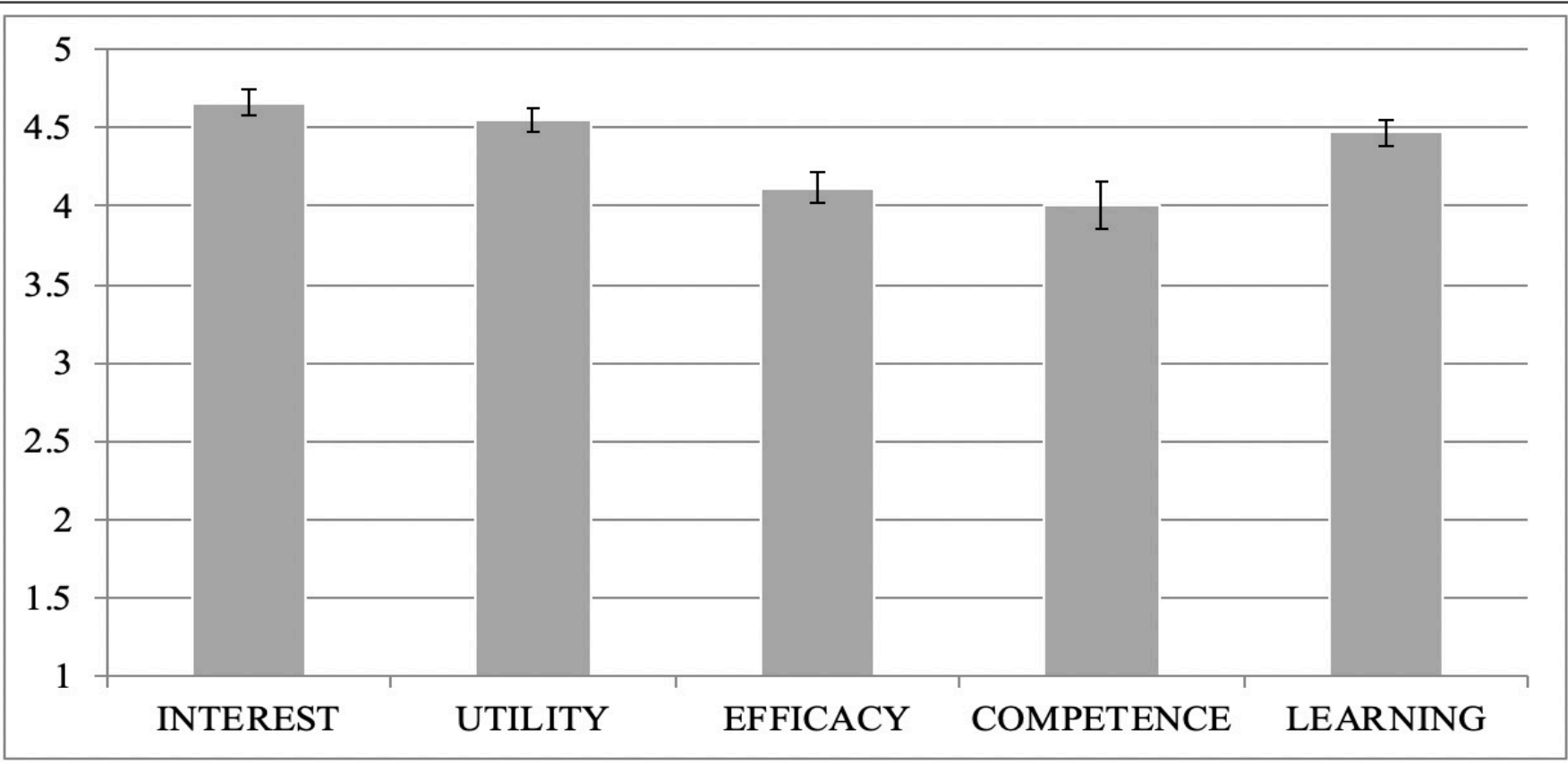

Figure 1. Likert scale questionnaire responses categorizes into common themes

seven studies $(8,10-15)$ which revealed that the majority of designs consisted of clerkship (near-peer) students teaching pre-clerkship students. To our knowledge, studies evaluating pre-clerkship students teaching POCUS to other pre-clerkship students are very limited. Thus, we sought to evaluate the perceptions of students having been exposed to peer teachings during these workshops, where experienced preclerkship and clerkship students taught novice pre-clerkship students.

\section{MATERIALS AND METHODS}

\section{Ethics}

The Research and Ethics Board (Ottawa Heath Science Network) exempted this project as it was deemed a quality improvement study.

\section{Peer-led workshops}

Workshops were held for cardiac, MSK, aorta, and eFAST POCUS scans. The workshops were peer-led sessions with a train-thetrainer session held prior to the workshop. Students with prior experience in POCUS (completed POCUS courses/electives, attended POCUS conferences/competitions, recommended by expert physicians) were identified as eligible peer leaders by workshop organizers. The peer leaders were given preparatory materials and attended a train-the-trainer session led by a physician expert prior to the workshop. At these sessions; peer leaders were trained on the relevant scanning technique and instructed on how to teach workshop participants. All workshops identified in this study were led by peer leaders in years 2-4 of their medical training.
Students participated in 3-hour POCUS workshops. The workshop format consisted of a 30-minute large group seminar where they were lectured about the scans, followed by 2.5 hours of scanning sessions in a small group (4-6 people). The small group sessions were led by a peer-leader. To ensure quality control, 1-2 physician experts were also present at the workshops to rotate through the stations to address any inquiries that arose.

\section{Perception Surveys}

Surveys were sent to all students who attended a POCUS workshop retroactively by email using SurveyMonkey. Completion of the surveys was voluntary. The surveys assessed five primary categories: I) self-perceived utility of POCUS, II) efficacy of the peer-led format, III) competence of the peerteachers, IV) learning experience, and V) POCUS interest and motivation. Each question was scored on a Likert scale from 1 (Strongly Disagree) to 5 (Strongly Agree). Quantitative analysis was performed and the mean, standard deviation, and confidence interval (alpha $=0.05$ ) were calculated. Qualitative analysis was also performed using thematic analysis methodology. Key words in the open-ended comment survey responses by students were recorded into an electronic log book. A reviewer then grouped keywords into categories based on their similarity.

\section{RESULTS}

Participation

118 students attended at least 1 POCUS workshop during 
the 2018-2019 academic year at the University of Ottawa. Perception surveys $(n=45)$ were completed by participants for a $38 \%$ response rate. Seven participants attended one workshop, 14 participants attended two workshops, and 24 participants attended three or more workshops.

\section{Quantitative analysis}

Participants who attended the workshop strongly agreed (4.55 \pm 0.07 ) that POCUS is a useful skill to learn during pre-clerkship, for use both as a clerk and as a physician. Participants also agreed $(4.12 \pm 0.10)$ that a peer-led format is effective for teaching POCUS and agreed $(4.00 \pm 0.15)$ that the peerteachers running small-group sessions were competent to teach and perform POCUS scans. Participants strongly agreed $(4.47 \pm 0.08)$ that peer-led POCUS workshops increased their knowledge. Finally, participants strongly agreed (4.66 \pm 0.08$)$ that peer-led workshops increased both their interest in and their motivation to learn POCUS. These results are summarized in Figure 1. When survey responses were analyzed dependent on the number of workshops that participants attended, the same trends were observed in all three groups (see Figure 2).

\section{Qualitative analysis}

Adding open-ended comments was a recommended, but not mandatory, portion of the distributed survey to participants. Twenty-five open-ended comments were submitted. Of these, 24 discussed self-perceived strengths of the peerled workshops, and one comment provided constructive feedback for future events. Thematic analysis highlighted four categories of positive feedback: trainer competence, learner comfort, situational teaching, and opportunity to practice. Participants felt confident that their peer-leaders had adequate knowledge and scanning skills to appropriately train them in POCUS. Participants also felt comfortable in the small-group session learning environment. Additionally, participants felt that the similar level of training between them and the peerleaders helped tailor teaching in a beneficial fashion. Finally, participants felt adequate time to practice each skill was provided. Thematic analysis also highlighted one category of constructive criticism: 1) inadequate preparatory resources. Participants felt that they would have benefited from receiving learning material to prepare, prior to each workshop.

\section{DISCUSSION}

Previous studies at Harvard and McMaster University have shown that pre-clerkship medical students are able to learn POCUS effectively in small-group settings $(16,17)$. The major advantage of this format is it maximizes the hands-on scanning time so that students can practice the techniques and understand the nuances of performing a scan. However, it is difficult to amass enough qualified faculty instructors to teach in a small group setting. Our approach mitigated the lack of instructors by employing a peer-led model comprised of experienced medical students leading the small group sessions. To ensure quality of instruction, the peer-leaders are trained prior to the session ("train-the-trainer") by a faculty expert. In order to maintain a high standard of quality assurance, there are faculty experts who rotate between small groups, helping with image interpretation and image generation while providing clinically relevant applications. Peer-led sessions are increasingly used in medical schools, and have been proven effective for teaching physical exam (18), procedural skills (11) and certain POCUS scans (19).

Resultsfrom our surveys show strong support for all 5 categories that were assessed: I) self-perceived utility of POCUS, II) efficacy of the peer-led format, III) competence of the peer-teachers, IV) learning experience, and V) POCUS interest and motivation. Positive perceptions were independent of the number of workshops attended (1 to $3+$ ). Our data shows that our peerled small group sessions with a rotating expert is an effective method for teaching POCUS to novice learners. Workshop participants were pleased with the learning experience and found the peer-leaders to be technically competent and effective teachers. Our data is consistent with previous studies where peer teachers are rated as effective teachers (14). A teaching strength of peer teachers is their familiarity with the curriculum and ability to tailor teaching towards the student's current knowledge (19). Participants received ample hands-on scanning time, which is a major advantage of small group format, without compromise to the instruction quality. Participants reported increased knowledge in POCUS, motivation to seek out further training and a willingness to use POCUS in clinical settings. Our results match up with previous studies which show how peer teachers can increase POCUS knowledge on par with clinical staff (10). Therefore, peer-led workshops are a resource-effective teaching approach which leads to a positive learning experience, while overcoming the barrier of limited availability from faculty instructors.

Minimal access to a proper ultrasound curriculum is a challenge in rural healthcare settings, where geographical barriers lead to a shortage of certified ultrasound instructors and access to an ultrasound course. Peer-led workshops can be used to 
provide ultrasound training to novice practitioners in these settings. A possible format could involve peer-led workshops with an expert available through videoconference, where the most experienced person(s) can train their colleagues with a POCUS expert (who are generally based out of tertiary care centers) available through video link. Videoconference approaches have been used effectively to train healthcare professionals, overcoming geographical barriers (20-22). As learners become proficient, they can become peer-leaders which will propagate and sustain POCUS education in isolated communities. The same phenomenon has occurred at our medical school where some workshop participants developed competency with POCUS and started teaching their colleagues.

Participant feedback on workshops was generally positive. As previously mentioned, four overarching themes were identified through qualitative analysis (see Table 1). The first is that learners felt more comfortable when taught by peers than by expert physicians. Previous studies have reported that peerled workshops increased learner comfort. In OSCE preparation near-peer workshops, participants reported that learning was more relevant to assessment, at an appropriate level of difficulty and delivered in a less threatening environment than other methods of teaching (23). Secondly, survey respondents reported that they felt the trainers were highly competent in POCUS. This has been a topic of increasing interest in the medical community over the last five years $(8,24)$. It has been shown that medical students are able to retain knowledge learned in POCUS workshops longitudinally (24), which supports the conclusion that these students will have the knowledge base required to teach others.

Participants also reported the theme of useful situational teaching, which refers to synchronizing the topics of our ultrasound workshops with the corresponding system being taught at the time in the undergraduate medical curriculum. For example, the cardiac POCUS workshop was given at the same time as the cardiac block, ensuring that students had basic anatomical and physiological knowledge of the heart. Research at the University of Ottawa has shown that situational system-by-system teaching can be useful in POCUS (24), which supports our participant observations. This has implications in rural settings where workshops can be catered to the needs of the rural team. Lastly, participants identified that ample practice time was provided to learn each POCUS skill. This is an important finding as recent research has shown that deliberate time for dedicated practice in POCUS is a requirement for adequate POCUS performance in medical practice (25).

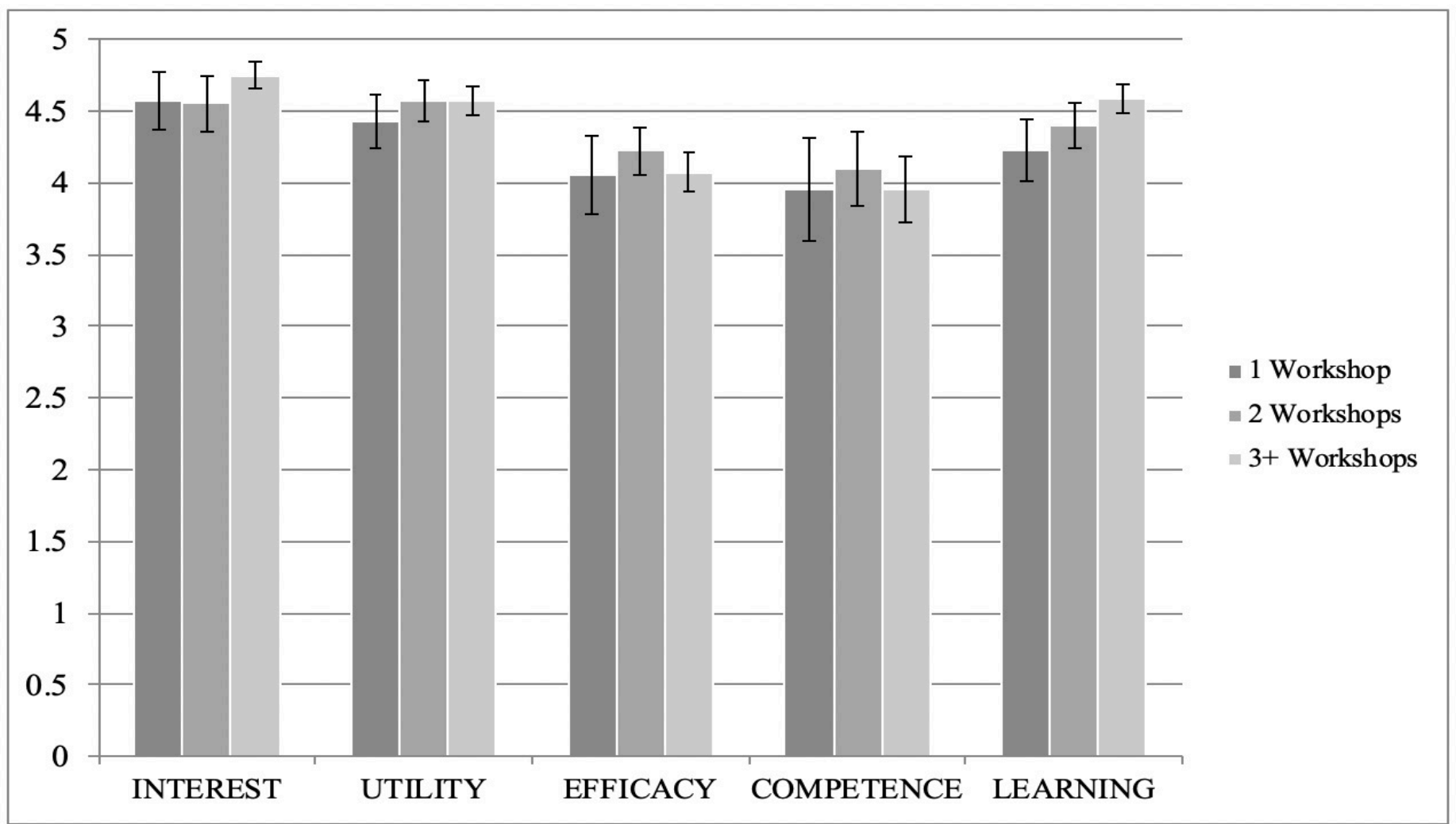

Figure 2. Likert scale questionnaire responses categorizes into common themes, dependent on number of workshops attended 
A final theme identified by participants was that preparatory resources were not provided prior to each workshop. Research at the University of Ottawa has shown that workshop participants show strong appreciation for pre-class preparation activities (26), as well as interactive, engaging small group activities. While our peer-led POCUS workshops demonstrated interactive, engaging small group activities, future work will aim to include preparatory material, as well as to assess participant satisfaction with these changes.

\section{Rurality and POCUS}

By enhancing diagnostic accuracy and streamlining management (27), the integration of POCUS in healthcare has been shown to improve patient safety $(28,29)$. Furthermore, several medical associations have recognized POCUS as a standard of care $(30,31)$. With a strong rationale for implementation, it is therefore not surprising that a recent Canadian study showed that POCUS use and training have increased over the last ten years (32). In parallel, POCUS clinical implementation, as an extension of the physical exam in rural medicine is steadily increasing (33). This is reflected by the recent surge of generalist/specialist and rural health care facilities purchasing POCUS equipment (34-36). Thus, with limited access to other formal imaging diagnostic modalities, POCUS has become an attractive ally to rural medicine.

A recent study evaluating rural POCUS' safety and impact on patient management found that rural physicians correctly diagnosed their patients approximately $90 \%$ of the time when diagnoses were compared with the results of formal imaging techniques (33). Furthermore, $87 \%$ of the POCUS scans improved diagnostic certainty, heightening physician confidence (33). POCUS also decreased hospital admission or patient transfer to urban centers (33). Similarly, another recent study revealed that $87 \%$ of patients, which included trauma casualties, patients with shock and patients with cardiorespiratory presentation, had their management changed after a pocket-sized bedside ultrasound assessment was done in a rural hospital (37).

Despite these promising findings, a study found that $3 \%$ of rural POCUS scans had the potential to unintentionally harm patients (33). Thus, this clinical adjunct is not without risk, as maintenance of knowledge and scanning techniques can be difficult in resource-scarce environments. This underscores the need for an ongoing POCUS training program in rural settings, ensuring that practitioners are adhering to high-quality and safe scopes of practices. Certain techniques such as peer-led workshop can therefore be used to make sure rural physicians with limited access maintain their skills.

\section{Peer-led and rurality}

With bedside ultrasound being incorporated in a wide array of specialties, several Canadian medical schools have started to implement POCUS in their curriculum (38). Despite this, certain barriers still exist around the technology's use in rural setting. As a recent Canadian study concluded, quality assurance and an inability to maintain skills were major impediments to POCUS use in rural settings (39). Peer-led POCUS workshops are a solution to this problem by empowering local experts, who in turn catalyze the training, continuity of skill and ultimately the confidence of their peers. In turn, this model then ensures knowledge sustainability and POCUS clinical expansion. Furthermore, the peer leader does not need to be a traditional sonographer, as generalists and nurses have demonstrated diagnostic exactness after short training sessions (40).

Additionally, early exposure to ultrasound training workshops in pre-clerkship years has been shown to be an effective teaching intervention for the acquisition of image generation (41-46) and interpretation $(16,41,47,48)$ skills. This early exposure, coupled with longitudinal POCUS training have the potential to increase rural physicians' confidence to perform bedside ultrasonography, mitigating a major barrier.

\section{Limitations}

While the advantages of near-peer POCUS teaching have been highlighted, this appraisal of near-peer POCUS is not without its drawbacks. While we have highlighted the disadvantages of peer leaders over clinical staff, this investigation provides no evidence to compare the two objectively. Future work will aim to quantify this comparison in a more formal and objective fashion. Furthermore, many of the conclusions reached are based on subjective assessments of learning, without the use of a validated knowledge assessment tool. For this reason, the ability to objectively compare this study to others of similar design will be impaired. Lastly, with a response rate of $38 \%$, a selection bias might have been present. It is possible that students experiencing more positive outcomes stemming from the workshops night have contributed to a larger portion of the study participants, due to their enthusiasm and appreciation of the clinical sessions.

Peer-led teaching has its drawbacks. Compared to clinical staff, 
peer tutors do not have the experience to point out the clinical relevance of scans, perform scans on technically challenging patients or interpret abnormal or normally variant images. We mitigated these drawbacks by having clinical staff rotate through the different tutorial groups to address any technical inquiries or shed light on the clinical relevance of certain scans.

\section{REFERENCES}

1. Topping KJ. The effectiveness of peer tutoring in further and higher education: A typology and review of the literature. High Educ. 1996 Oct;32(3):321-45.

2. Benè $\mathrm{KL}$, Bergus $\mathrm{G}$. When learners become teachers: a review of peer teaching in medical student education. Fam Med. 2014 Dec;46(10):783-7.

3. Yu T-C, Wilson NC, Singh PP, Lemanu DP, Hawken SJ, Hill AG. Medical students-as-teachers: a systematic review of peer-assisted teaching during medical school. Adv Med Educ Pract. Jun;2011;2:157-72.

4. Soriano RP, Blatt B, Coplit L, CichoskiKelly E, Kosowicz L, Newman $L$, et al. Teaching medical students how to teach: a national survey of students-as-teachers programs in U.S. medical schools. Acad Med. 2010 Nov;85(11):1725-31.

5. Tayler N, Hall S, Carr NJ, Stephens JR, Border S. Near peer teaching in medical curricula: integrating student teachers in pathology tutorials. Med Educ Online [Internet]. 2015 Jun;20. Available from: https://www. ncbi.nlm.nih.gov/pmc/articles/PMC4488334/

6. Hall S, Stephens J, Andrade T, Davids J, Powell M, Border S. Perceptions of junior doctors and undergraduate medical students as anatomy teachers: Investigating distance along the near-peer teaching spectrum. Anat Sci Educ. 2014 Jun;7(3):242-7.

7. Nelson AJ, Nelson SV, Linn AMJ, Raw LE, Kildea HB, Tonkin AL. Tomorrow's educators...today? Implementing near-peer teaching for medical students. Med Teach. 2013;35(2):156-9.

8. DesJardin JT, Ricceri SK, Brown SD, Webb EM, Naeger DM, Teismann NA. A Near-peer Point-of-care Ultrasound Elective for Medical Students: Impact on Anatomy Knowledge, Perceptions About Ultrasound, and Selfreported Skill Level. Academic Radiology. 2017 Jun;24(6):772-9.

9. Shankar H, Pagel PS. Potential Adverse Ultrasound-related Biological EffectsA Critical Review. Anesthes. 2011 Nov;115(5):1109-24.

10. Jeppesen KM, Bahner DP. Teaching bedside sonography using peer mentoring: a prospective randomized trial. J Ultrasound Med. 2012 Mar;31(3):455-9.

11. Knobe M, Münker R, Sellei RM, Holschen M, Mooij SC, Schmidt-Rohlfing B, et al. Peer teaching: a randomised controlled trial using student-teachers to teach musculoskeletal ultrasound. Med Educ. 2010 Feb;44(2):148-55.

12. Kühl M, Wagner R, Bauder M, Fenik $Y$, Riessen R, Lammerding-Köppel $M$, et al. Student tutors for hands-on training in focused emergency echocardiography - a randomized controlled trial. BMC Med Educ. 2012 Oct; 12:101

13. Dickerson J, Paul K, Vila P, Whiticar R. The role for peer-assisted ultrasound teaching in medical school. Clin Teach. 2017 Jun;14(3):170-4.

14. Ahn JS, French AJ, Thiessen MEW, Kendall JL. Training peer instructors for a combined ultrasound/physical exam curriculum. Teach Learn Med. 2014;26(3):292-5.

15. Fox JC, Chiem AT, Rooney KP, Maldonaldo G. Web-based lectures, peer instruction and ultrasound-integrated medical education. Med Educ. 2012 Nov;46(11):1109-10.

16. Rempell JS, Saldana F, DiSalvo D, Kumar N, Stone MB, Chan W, et al. Pilot Point-of-Care Ultrasound Curriculum at Harvard Medical School: Early Experience. West J Emerg Med. 2016 Nov; 17(6):734-40.

17. Safavi $A$, Shi $Q$, Ding $M$, et al. Structured, Small-group Hands-on Teaching Sessions Improve Pre-clerk Knowledge and Confidence in Pointof-care Ultrasound Use and Interpretation. Cureus Oct;10(10): e3484. doi:10.7759/cureus.3484

18. Weyrich $P$, Celebi N, Schrauth $M$, Möltner A, Lammerding-Köppel $M$,
Nikendei C. Peer-assisted versus faculty staff-led skills laboratory training: a randomised controlled trial. Med Educ. 2009 Feb;43(2):113-20.

19. Tolsgaard MG, Gustafsson A, Rasmussen MB, Høiby P, Müller CG, Ringsted C. Student teachers can be as good as associate professors in teaching clinical skills. Med Teach. 2007 Sep;29(6):553-7.

20. Fahey A, Day NA, Gelber H. Tele-education in child mental health for rural allied health workers. J Telemed Telecare. 2003;9(2):84-8.

21. DuBose TJ, Bittengle J, Donaldsont R. Diagnostic Medical Sonography, Interactive Video, and Distance Learning. Journal of Diagnostic Medical Sonography. 1997 May;13(3):146-52.

22. Berndt A, Murray CM, Kennedy K, Stanley MJ, Gilbert-Hunt S. Effectiveness of distance learning strategies for continuing professional development (CPD) for rural allied health practitioners: a systematic review. BMC Med Educ. 2017 Jul;17(1):117.

23. de Menezes S, Premnath D. Near-peer education: a novel teaching program. Int J Med Educ. 2016 May 30;7:160-7.

24. Edgar L, Fraccaro L, Park L, Maclsaac J, Pageau P, Ramnanan C, et al. MP16: Which PoCUS skills are retained over time for medical students? Canadian Journal of Emergency Medicine. 2019 May;21(S1):S47-8.

25. Hayward M, Chan T, Healey A. Dedicated time for deliberate practice: one emergency medicine program's approach to point-of-care ultrasound (PoCUS) training. CJEM. 2015 Sep;17(5):558-61.

26. Ramnanan CJ, Pound LD. Advances in medical education and practice: student perceptions of the flipped classroom. Adv Med Educ Pract. 2017 Jan;8:63-73.

27. Lyon $M$, Blaivas $M$, Brannam L. Use of emergency ultrasound in a rural $E D$ with limited radiology services. Am J Emerg Med. 2005 Mar;23(2):212-4.

28. Moore CL, Copel JA. Point-of-Care Ultrasonography. New England Journal of Medicine. 2011 Feb;364(8):749-57.

29. Arienti V, Camaggi V. Clinical applications of bedside ultrasonography in internal and emergency medicine. Intern Emerg Med. 2011 Jun 1;6(3):195-201.

30. Thomas HA, Beeson MS, Binder LS, Brunett PH, Carter MA, Chisholm CD, et al. The 2005 Model of the Clinical Practice of Emergency Medicine: the 2007 update. Acad Emerg Med. 2008 Aug;15(8):776-9.

31. Emergency Ultrasound Guidelines. Annals of Emergency Medicine. 2009 Apr;53(4):550-70.

32. Leschyna M, Hatam E, Britton S, Myslik F, Thompson D, Sedran R, et al. Current State of Point-of-care Ultrasound Usage in Canadian Emergency Departments. Cureus. 2019 Mar;11(3):e4246.

33. Nixon G, Blattner K, Koroheke-Rogers M, Muirhead J, Finnie WL, Lawrenson $\mathrm{R}$, et al. Point-of-care ultrasound in rural New Zealand: Safety, quality and impact on patient management. Australian Journal of Rural Health. 2018;26(5):342-9.

34. Glazebrook R, Manahan D, Chater AB. Evaluation of an ultrasound program (intermediate obstetric and emergency medicine) for Australian rural and remote doctors. Aust J Rural Health. 2005 Oct;13(5):295-9.

35. Glazebrook R, Manahan D, Chater B, Barker P, Row D, Steele B, et al. Educational needs of rural and remote Australian non-specialist medical practitioners for obstetric ultrasound. Aust J Rural Health. 2004 Apr;12(2):73-80.

36. Léger $P$, Fleet $R$, Maltais-Giguère J, Plant J, Piette É, Légaré $F$, et al. A majority of rural emergency departments in the province of Quebec use point-of-care ultrasound: a cross-sectional survey. BMC Emerg Med. 2015 Dec;15:36.

37. Epstein D, Petersiel N, Klein E, Marcusohn E, Aviran E, Harel R, et al. Pocketsize point-of-care ultrasound in rural Uganda - A unique opportunity "to see", where no imaging facilities are available. Travel Med Infect Dis. 2018 Jun;23:87-93.

38. Steinmetz $P$, Dobrescu O, Oleskevich $S$, Lewis J. Bedside ultrasound education in Canadian medical schools: A national survey. Can Med Educ J. Mar;2016;7(1):e78-86.

39. Micks T, Sue K, Rogers P. Barriers to point-of-care ultrasound use in rural emergency departments. CJEM. 2016 Nov; 18(6):475-9.

40. Wanjiku GW, Bell G, Wachira B. Assessing a novel point-of-care ultrasound training program for rural healthcare providers in Kenya. BMC Health Serv 
Res [Internet]. 2018 Aug;18. Available from: https://www.ncbi.nlm.nih. gov/pmc/articles/PMC6091199/

41. Cawthorn TR, Nickel C, O'Reilly M, Kafka H, Tam JW, Jackson LC, et al. Development and Evaluation of Methodologies for Teaching Focused Cardiac Ultrasound Skills to Medical Students. Journal of the American Society of Echocardiography. 2014 Mar;27(3):302-9.

42. Denny SP, Minteer WB, Fenning RTH, Aggarwal S, Lee DH, Raja SK, et al. Ultrasound curriculum taught by first-year medical students: A four-year experience in Tanzania. World J Emerg Med. 2018;9(1):33-40.

43. Dinh VA, Dukes WS, Prigge J, Avila M. Ultrasound Integration in Undergraduate Medical Education: Comparison of Ultrasound Proficiency Between Trained and Untrained Medical Students. Journal of Ultrasound in Medicine. Sep;2015;34(10):1819-24.

44. Fu JY, Krause C, Krause R, Mccoy J, Schindler A, Udrea DS, et al. Integration of Point-of-Care Ultrasound Training into Undergraduate Medical Curricula--A Perspective from Medical Students. J Med Educ Curric Dev [Internet]. 2016 May;3. Available from: https://www.ncbi.nlm.nih.gov/ pmc/articles/PMC5736279/

45. Kobal SL, Trento L, Baharami S, Tolstrup K, Naqvi TZ, Cercek B, et al, Comparison of Effectiveness of Hand-Carried Ultrasound to Bedside Cardiovascular Physical Examination. The American Journal of Cardiology. 2005 Oct;96(7):1002-6.

46. Mai T, Woo MY, Boles K, Jetty P. Point-of-Care Ultrasound Performed by a Medical Student Compared to Physical Examination by Vascular Surgeons in the Detection of Abdominal Aortic Aneurysms. Annals of Vascular Surgery. 2018 Oct;52:15-21.

47. Shokoohi H, Boniface K, Kaviany P, Armstrong P, Calabrese K, Pourmand A. An Experiential Learning Model Facilitates Learning of Bedside Ultrasound by Preclinical Medical Students. Journal of Surgical Education. 2016 Mar;73(2):208-14.

48. Udrea DS, Sumnicht A, Lo D, Villarreal L, Gondra S, Chyan R, et al. Effects of Student-Performed Point-of-Care Ultrasound on Physician Diagnosis and Management of Patients in the Emergency Department. The Journal of Emergency Medicine. 2017 Jul;53(1):102-9. 